\title{
Subgroup analysis of the influence of body mass index on the association between serum lipids and cognitive function in Chinese population
}

\author{
Jiang $\mathrm{Li}^{i^{*}}$ (D), Yongtong $\mathrm{CaO}^{1}$ and Cheng $\mathrm{XiaO}^{2,3^{*}}$
}

\begin{abstract}
Background: Previous studies reported that the association between lipid levels and cognitive function is related with gender, age and specific cognitive domains, but the influence of body mass index (BMI) on this association is limited. This triggered interest in exploring how serum lipids relate to cognitive function in different subgroups.

Methods: Data was collected from 2009 wave and 2015 wave of China Health and Nutrition Survey (CHNS). Multivariable linear regression analyses examined serum lipids level as predictors of sex-and age-specific measure of cognitive function in different BMI levels, which were adjusted for nationality, BMI, systolic blood pressure (SBP), diastolic blood pressure (DBP), smoking status, alcohol consumption and education level.

Results: Cognitive function score have different concentration curves in serum lipids quartile levels in different BMI categories. After adjustment for confounding factors, serum TG was positively associated with cognitive function score in underweight ( $\beta \pm$ SE: $2.06 \pm 0.88, P=0.023$ ) and obese ( $\beta \pm$ SE: $1.44 \pm 0.71, P=0.045)$ male group, and serum $\mathrm{HDL}-\mathrm{C}$ was positively associated with cognitive function score in overweight $(\beta \pm \mathrm{SE}: 1.89 \pm 0.92, P=0.041)$ and obese ( $\beta \pm$ SE: $5.04 \pm 1.62, P=0.002$ ) female group. Serum TC was negatively associated with cognitive function score in overweight ( $\beta \pm$ SE: $-2.55 \pm 1.26, P=0.043$ ) mid-life adults, and serum HDL-C was positively associated with cognitive function score in overweight ( $\beta \pm$ SE: $2.15 \pm 0.94, P=0.022$ ) and obese ( $\beta \pm S E: 5.33 \pm 2.07, P=0.011)$ older adults.

Conclusion: The associations of serum lipids with cognitive function were related with BMl levels and differed between gender and age groups. This result indicated that better nutritional status has superior cognitive function performance.

Keywords: Subgroup analysis, Body mass index, Cognitive function, Blood lipid profile, Chinese population, China health and nutrition survey
\end{abstract}

\footnotetext{
* Correspondence: lijiang1979@gmail.com; xc2002812@126.com

'Department of Laboratory Medicine, China-Japan Friendship Hospital, Beijing 100029, China

${ }^{2}$ Institute of Clinical Medicine, China-Japan Friendship Hospital, Beijing 100029, China

Full list of author information is available at the end of the article
}

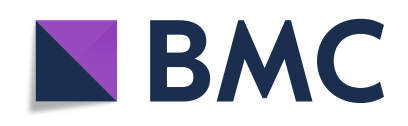

(- The Author(s). 2020 Open Access This article is licensed under a Creative Commons Attribution 4.0 International License, which permits use, sharing, adaptation, distribution and reproduction in any medium or format, as long as you give appropriate credit to the original author(s) and the source, provide a link to the Creative Commons licence, and indicate if changes were made. The images or other third party material in this article are included in the article's Creative Commons licence, unless indicated otherwise in a credit line to the material. If material is not included in the article's Creative Commons licence and your intended use is not permitted by statutory regulation or exceeds the permitted use, you will need to obtain permission directly from the copyright holder. To view a copy of this licence, visit http://creativecommons.org/licenses/by/4.0/. The Creative Commons Public Domain Dedication waiver (http://creativecommons.org/publicdomain/zero/1.0/) applies to the data made available in this article, unless otherwise stated in a credit line to the data. 


\section{Introduction}

Cognitive impairment is an obvious and important disorder among the elderly and affecting the life of the elderly, which is an intermediate stage between normal aging and dementia. It is especially important to test the physical and mental health and quality of life of elderly individuals [1]. This group of people represents a population at risk of developing dementia. In 2018, a systematic review showed that the pooled prevalence of mild cognitive impairment (MCI) in China was $14.71 \%$ and people of older age, of female sex, or living in rural areas or western China were associated with a higher prevalence of MCI [2]. In a study among of Chinese older adults aged 90 years and over [3], the prevalence of $\operatorname{cog}$ nitive impairment increased to $57.8 \%$ overall and up to $67.2 \%$ among women. Other studies have shown similar results $[4,5]$. These inconsistencies might be attributable to gender- and age-related differences in blood lipid profiles, aetiology of dementia and methods of cognitive assessment $[2,6]$.

Previous study speculated that associations of serum lipids with cognitive performance are inversely U-shaped or J-shaped [6]. These associations implied that participants with extremely low or high levels of serum lipids would be expected to show poorer cognitive performance. The possible pathophysiological mechanisms of high serum lipids with the risk of cognitive decline is that high level of cholesterol can contribute to an overproduction and accumulation of $\beta$-amyloid in the brain [7]. The possible explanation for low serum lipid levels with the risk of cognitive decline is the nutritional status of participants. Participants with malnutrition show alterations in the energetic profile, such as weight loss, reduced caloric, increased energy requirement, low lipid levels and cognitive function impairment $[8,9]$.

Two reviews concluded that high serum cholesterol associates with cognitive function and the association is strongly age-dependent $[10,11]$. However the associations between serum or plasma triglyceride (TG) and cognitive function were complicated and associated with body mass index (BMI) and gender (Table 1). Yin et al. [12] found that high normal plasma TG was association with preservation of cognitive function while lower concentrations were not in the Chinese oldest-old. Two studies reported that lower TG was associated with higher cognitive scores in most cognitive domains [13] and better short-term memory [15]. Lv et al. [14] found that TG was associated with Mini Mental Status Examination (MMSE) score, but after adjustment for central obesity and other confounding factors, it was not associated with the risk of cognitive impairment. Parthasarathy et al. [16] even found that TG levels are inversely correlated with executive function in non-demented elderly adults.
Most of research only focused on the total population and did not considered the influence of BMI on these associations, leading to some ambiguity with respect to potential BMI differences in serum lipids and cognitive function. So these inconsistent results and potential relationships triggered interest in exploring the influence of $\mathrm{BMI}$ on the association between serum lipids and cognitive function in different subgroups based on a nationally representative sample of the Chinese population.

\section{Methods \\ Setting}

The China Health and Nutrition Survey (CHNS) started in 1989. It was intended to represent a range of economic and demographic variation in China. Data of participants of CHNS came from 12 provinces (from north to south, including Heilongjiang, Liaoning, Shandong, Henan, Hubei, Hunan, Jiangsu, Guangxi, Guizhou, Ningxia, Shaanxi and Yunnan) and 3 municipal cities (Beijing, Shanghai and Chongqing). Blood biomarkers were tested for the first time in 2009. Details of the study design and sampling strategies are available at the World Wide Web site (https://www.cpc. unc.edu/projects/china) and elsewhere [17, 18].

All the documentation and procedures comply with Good Clinical Practice (GCP), Human Ethics Protocol Rules and related Chinese laws. The CHNS project was approved by the office of human research ethics of the University of North Carolina at Chapel Hill and the Human \& Clinical Research Ethics Committee of ChinaJapan Friendship Hospital (Study ID: 07-1963). Approved consent forms and other documents are available online at the World Wide Web site (http://apps.research.unc. edu/irb/index.cfm?event=home.dashboard.irbStudyManag ement\&irb_id=07-1963).

\section{Data collection methods}

The data of demographic, anthropometric, lifestyle, memory status and perceived stress index were collected by trained interviewers used a questionnaire. Height and weight were measured based on a standard protocol. Height was measured to the nearest $0.1 \mathrm{~cm}$, and weight in lightweight clothing was measured to the nearest 0.1 $\mathrm{kg}$. BMI was calculated as weight in $\mathrm{kg}$ divided by height in square metres.

Trained nurses drew fasting blood from participants' antecubital vein in the morning. Blood samples were treatment (centrifuged at $3000 \mathrm{~g}$ for $10 \mathrm{mins}$ at room temperature and separated into 9 aliquots) within $2 \mathrm{~h}$ of collection in local hospitals. Aliquots were storage in -80 degree freezers.

Serum TG (Lot number: 192AIF), total cholesterol (TC) (Lot number: 203AIG), high-density lipoprotein cholesterol (HDL-C) (Lot number: 548AIE) and lowdensity lipoprotein cholesterol (LDL-C) (Lot number: 


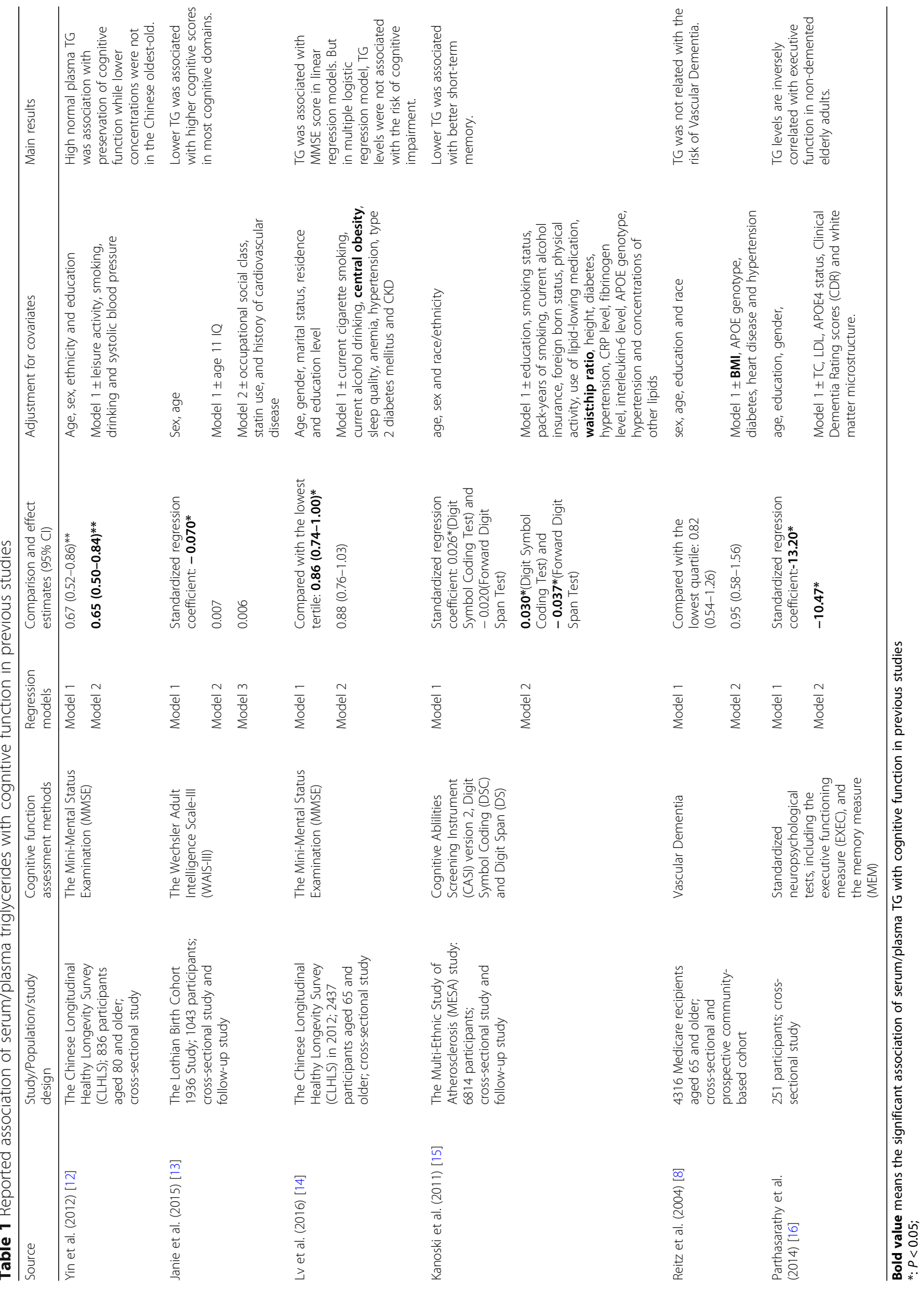


362AIG) were detected using the enzymatic colorimetric method (Kyowa Medex Co., Ltd., Takatsuki-shi, Osaka, Japan). The calibrators and control serums were provided by the department of laboratory medicine of China-Japan Friendship Hospital and had the same lot number.

\section{Definition of body size phenotypes and BMI levels}

Participants were classified as follows [19]:

Underweight: $\mathrm{BMI}<18.5 \mathrm{~kg} / \mathrm{m}^{2}$;

Normal weight: BMI $18.5-23.9 \mathrm{~kg} / \mathrm{m}^{2}$;

Overweight: BMI $24.0-27.9 \mathrm{~kg} / \mathrm{m}^{2}$;

Obese: BMI of $28-31.9 \mathrm{~kg} / \mathrm{m}^{2}$;

Severely obese: BMI $\geq 32.0 \mathrm{~kg} / \mathrm{m}^{2}$.

\section{Definition of age levels}

Participants were classified as follows [20]:

Mid-life adults: $<65$ years;

Older adults: $\geq 65$ years.

\section{Assessment of memory status and cognitive function}

The global cognitive score was calculated using composite scores of memory, counting back and subtraction scores. The cognitive screening items of questionnaire used in CHNS included a subset of items from the telephone interview for cognitive status-modified [21, 22]. The questionnaire included two questions for assessing self-reported memory status and four tests for testing memory performance. The first question asked about memory status: "How is your memory?" The response categories were "very good", "good", "OK", "bad" and "very bad". Those who reported "bad" or "very bad" were defined as having a poor memory. The second question asked about changes in memory status: "In the past twelve months, how has your memory changed?" The response categories were "improved", "stayed the same" and "deteriorated". Those who reported "deteriorated" were defined as self-reported memory decline.

The following four tests were related to cognitive function on specific memory tasks. Four tests were administered in the following order: 1) the first was a word list memory test for immediate memory, in which an examiner read a list of 10 unrelated words at 2-s intervals and immediately asked the participant to repeat to them as many words as possible in any order (score 10); 2) the following two tests were mind control ability tests in which an examiner counted backward from 20 to 1 (score 2) and calculated 100 minus 7 and subtracted 7 again and again (score 5); and 3) the last test was a test for delayed memory, in which a list of words were repeated to an examiner after a period of time (score 10). An orientation test was not included in the analysis as it was only assessed in 2015 wave. The cognitive function score was used to assess memory performance, which was the sum of the scores of the four tests and could range from 0 to 27 points. The Cronbach alpha internal consistency coefficient of this scale was 0.73 , which is above the acceptable cut-off value of 0.70 .

\section{Study population}

In total, 15,143 CHNS participants were included, and 5256 participants had complete memory status data. After excluding the participants with use lipid lowering agent, 4574 participants remained. After further excluding the participants with missing or incomplete gender, age and education level data, 4538 participants remained. Subsequently, 18 participants with missing BMI data and 2274 participants with missing biomarker data were excluded, 2246 participants (1120 men and 1126 women) remained (Fig. 1).

\section{Statistical methods}

The current study was restricted to 2246 participants to examine the influence of BMI on the association between serum lipids and cognitive function among Chinese population. For the baseline characteristics of participants, all data are shown as the means \pm standard deviations (SDs) for normal variables and as medians (interquartile ranges) for skewed variables. Differences in characteristics between gender and age subgroups were tested for significance. The unpaired t-test or Mann-Whitney $\mathrm{U}$ test was used to compare the differences between continuous variables, and the chi-square test was used for categorical variables.

Multivariable linear regression analyses examined serum lipids level as predictors of gender- and age-specific measure of cognitive function in different BMI levels, which were adjusted for confounding factors, including gender, age, nationality, BMI, systolic blood pressure (SBP), diastolic blood pressure (DBP), smoking status, alcohol consumption and education level. The statistical analysis was performed with program R 3.4.3.

\section{Results}

\section{Baseline characteristics of the study participants}

The baseline characteristics of the participants were described separately for different gender subgroups (1120 men and 1126 women) and age subgroups (1160 midlife adults and 1086 older adults) (Table 2). A total of 2246 participants, aged $65.64 \pm 7.52$ years (range, 55-94 years) with a BMI of $23.98 \pm 3.54 \mathrm{~kg} / \mathrm{m}^{2}$, were included in this study. The women showed higher BMI levels $(24.58 \pm 3.64$ vs. $23.74 \pm 3.45, P<0.001)$, lower rates of current smoking $(4.17 \%$ vs. $53.13 \%, P<0.001)$ and alcohol consumption $(4.88 \%$ vs. $50.54 \%, P<0.001)$, lower education level and poorer self-reported memory status than the men. The women also showed higher serum 


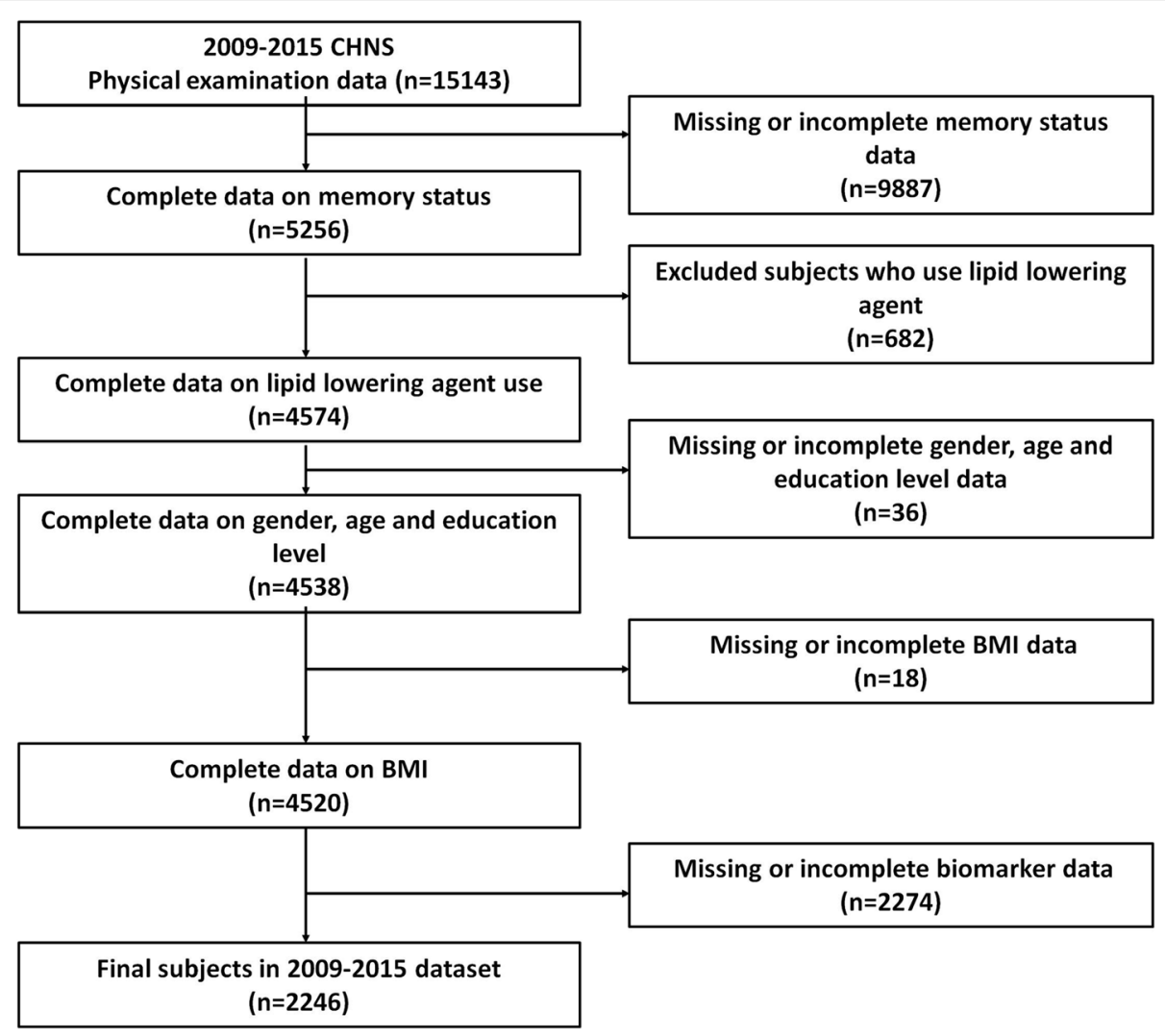

Fig. 1 Flow chart of the participant selection

lipids levels than the men, including TG $[1.44(1.23)$ vs. 1.23(1.10), $P<0.001]$, TC [5.12(1.25) vs. $4.80(1.22), P<$ $0.001]$, HDL-C $[1.43(0.48)$ vs. $1.38(0.49), P=0.001]$ and LDL-C [3.21(1.21) vs. 2.96(1.14), $P<0.001]$. The older adults showed higher SBP levels (139.45 \pm 19.48 vs. $133.87 \pm 18.38, P<0.001)$, lower BMI levels $(24.00 \pm 3.64$ vs. $24.35 \pm 3.56, P=0.013)$ and cognitive function score $(12.34 \pm 4.76$ vs. $13.65 \pm 4.63, P<0.001)$, lower rates of alcohol consumption $(23.66 \%$ vs. $31.38 \%, P<0.001)$, lower education level and poorer self-reported memory status than mid-life adults. Other characteristics were not significantly different.

Distribution of cognitive function in quartile levels of serum lipids in different BMI categories

Gender- and age-specific distribution of cognitive function in different BMI categories were shown in Fig. $2 a$ and b. Participants were divided into four groups according to quartile levels of serum lipids. Cognitive function scores have different curves in different BMI categories.

\section{Subgroup analysis of the influence of BMI on the} association between serum lipids and cognitive function Multivariable linear regression analyses were performed separately to examine gender- and age-specific associations between serum lipids and cognitive function in different BMI categories (Table 3). After adjustment for confounding factors, serum TG was positively associated with cognitive function score in underweight $(\beta \pm$ SE: $2.06 \pm 0.88, P=$ $0.023)$ and obese $(\beta \pm$ SE: $1.44 \pm 0.71, P=0.045)$ male group, and serum HDL-C was positively associated with cognitive function score in overweight $(\beta \pm$ SE: $1.89 \pm 0.92, P=0.041)$ and obese $(\beta \pm$ SE: $5.04 \pm 1.62, P=0.002)$ female group. Serum TC was negatively associated with cognitive function score in overweight $(\beta \pm \mathrm{SE}:-2.55 \pm 1.26, P=0.043)$ midlife adults, and serum HDL-C was positively associated with cognitive function score in overweight $(\beta \pm$ SE: $2.15 \pm 0.94$, $P=0.022)$ and obese $(\beta \pm$ SE: $5.33 \pm 2.07, P=0.011)$ older adults.

\section{Discussion}

This study investigated the influence of BMI on the association between serum lipids and cognitive function in different subgroups based on a nationally representative sample of the Chinese elderly population for the first time. A total of 2246 participants (1120 men and 1126 women), aged $65.64 \pm 7.52$ years (range, 55-94 years) with a BMI of $23.98 \pm 3.54 \mathrm{~kg} / \mathrm{m}^{2}$, were included in this study. Some of the results of this study were consistent with previous research results, and with general cognition. 
Table 2 Baseline characteristics of the study participants in different subgroups

\begin{tabular}{|c|c|c|c|c|c|c|}
\hline \multirow[t]{3}{*}{ Item } & \multicolumn{6}{|l|}{ Subgroups } \\
\hline & \multicolumn{3}{|l|}{ Sex groups } & \multicolumn{3}{|l|}{ Age groups } \\
\hline & Men & Women & $P$ value & Mid-life adults & Older adults & $P$ value \\
\hline$n$ & 1120 & 1126 & & 1160 & 1086 & \\
\hline Age, years & $65.87 \pm 7.71$ & $65.29 \pm 7.25$ & 0.139 & $59.70 \pm 2.78$ & $71.87 \pm 5.58$ & $<0.001$ \\
\hline $\mathrm{BMI}, \mathrm{kg} / \mathrm{m}^{2}$ & $23.76 \pm 3.48$ & $24.61 \pm 3.67$ & $<0.001$ & $24.35 \pm 3.56$ & $24.00 \pm 3.64$ & 0.013 \\
\hline SBP, mmHg & $136.45 \pm 18.83$ & $136.68 \pm 19.42$ & 0.964 & $133.87 \pm 18.38$ & $139.45 \pm 19.48$ & $<0.001$ \\
\hline $\mathrm{DBP}, \mathrm{mmHg}$ & $83.49 \pm 10.91$ & $82.36 \pm 10.18$ & 0.069 & $83.36 \pm 10.69$ & $82.46 \pm 10.41$ & 0.111 \\
\hline Nationality, Han, n(\%) & $992(88.57)$ & $1011(89.79)$ & 0.390 & $1053(90.78)$ & $950(87.48)$ & 0.014 \\
\hline Smokers, n(\%) & $595(53.13)$ & $47(4.17)$ & $<0.001$ & $339(29.22)$ & $303(27.90)$ & 0.518 \\
\hline Alcohol use/last year, n(\%) & $566(50.54)$ & $55(4.88)$ & $<0.001$ & $364(31.38)$ & $257(23.66)$ & $<0.001$ \\
\hline Education level, n(\%) & & & $<0.001$ & & & $<0.001$ \\
\hline Low & $426(38.04)$ & $678(60.21)$ & & $463(39.91)$ & $641(59.02)$ & \\
\hline Medium & $565(50.45)$ & $352(31.26)$ & & $597(51.47)$ & $320(29.47)$ & \\
\hline High & $129(11.52)$ & $96(8.53)$ & & $100(8.62)$ & $125(11.51)$ & \\
\hline \multicolumn{2}{|l|}{ Self-reported memory status, n(\%) } & & 0.012 & & & $<0.001$ \\
\hline Very good & $97(8.66)$ & $67(5.95)$ & & $117(10.09)$ & $47(4.33)$ & \\
\hline Good & $293(26.16)$ & $260(23.09)$ & & $339(29.22)$ & $214(19.71)$ & \\
\hline OK & $520(46.43)$ & $544(48.31)$ & & $549(47.33)$ & $515(47.42)$ & \\
\hline Bad & $191(17.05)$ & $237(21.05)$ & & $142(12.24)$ & $286(26.34)$ & \\
\hline Very bad & $19(1.70)$ & $18(1.60)$ & & $13(1.12)$ & $24(2.21)$ & \\
\hline \multicolumn{3}{|c|}{ Self-reported changes in memory status, n(\%) } & 0.011 & & & $<0.001$ \\
\hline Improved or stayed the same & $614(54.82)$ & $553(49.11)$ & & $697(60.09)$ & $470(43.28)$ & \\
\hline Deteriorated & $506(45.18)$ & $573(50.89)$ & & $463(39.91)$ & $616(56.72)$ & \\
\hline Cognitive function score & $13.20 \pm 4.71$ & $12.83 \pm 4.76$ & 0.061 & $13.65 \pm 4.63$ & $12.34 \pm 4.76$ & $<0.001$ \\
\hline \multicolumn{7}{|l|}{ Serum lipids } \\
\hline $\mathrm{TG}, \mathrm{mmol} / \mathrm{L}$ & $1.23(1.10)$ & $1.44(1.23)$ & $<0.001$ & $1.35(1.23)$ & $1.34(1.12)$ & 0.218 \\
\hline $\mathrm{TC}, \mathrm{mmol} / \mathrm{L}$ & $4.80(1.22)$ & $5.12(1.25)$ & $<0.001$ & $4.96(1.25)$ & 4.99 (1.29) & 0.911 \\
\hline $\mathrm{HDL}, \mathrm{mmol} / \mathrm{L}$ & $1.38(0.49)$ & $1.43(0.49)$ & 0.001 & $1.42(0.50)$ & $1.40(0.47)$ & 0.652 \\
\hline $\mathrm{LDL}, \mathrm{mmol} / \mathrm{L}$ & $2.96(1.14)$ & $3.21(1.22)$ & $<0.001$ & 3.06 (1.19) & 3.09 (1.19) & 0.173 \\
\hline
\end{tabular}

Values are presented as the mean $\pm \mathrm{SD}$, median (interquartile range) or number (percent)

Bold value means $P<0.05$

$B M I$ body mass index, SBP systolic blood pressure, DBP diastolic blood pressure, $T G$ triglycerides, $T C$ total cholesterol, $H D L-C$ high-density lipoprotein cholesterol, $L D L-C$ low-density lipoprotein cholesterol

Serum TC was negatively associated with cognitive function score in overweight mid-life adults, and serum HDL$\mathrm{C}$ was positively associated with cognitive function score in overweight and obese female group and older adults. But some of the results were inconsistent with general cognition. Serum TG was positively associated with cognitive function score in underweight and obese male group. It confirmed that serum lipids were related with cognitive function differed between gender- and age-subgroups in different BMI categories, and indicated that nutritional status was related with cognitive function performance.

Accumulating evidence suggests that lipid levels are associated with cognitive function and dementia, but results of previous studies showed that the association between lipid levels and cognitive function might be complicated and related with gender $[6,11]$, age [13] and specific cognitive domains [3]. Lu et al. [6] speculated that associations of serum lipids with cognitive performance is inversely U-shaped or J-shaped. Solomon et al. [23] reported a bidirectional relationship between $\mathrm{TC}$ and poor cognitive status and observed a tendency to an interaction between sex and TC changes over time in relation to late-life cognition, but due to size limitation, they could not draw definite conclusions. Ancelin et al. [24] reported that hypercholesterolemic late-life pattern (high TC, low HDL-C, high LDL-C) was related to an increased risk of cognitive function impairment in elderly men. But they also observed an unexpected 


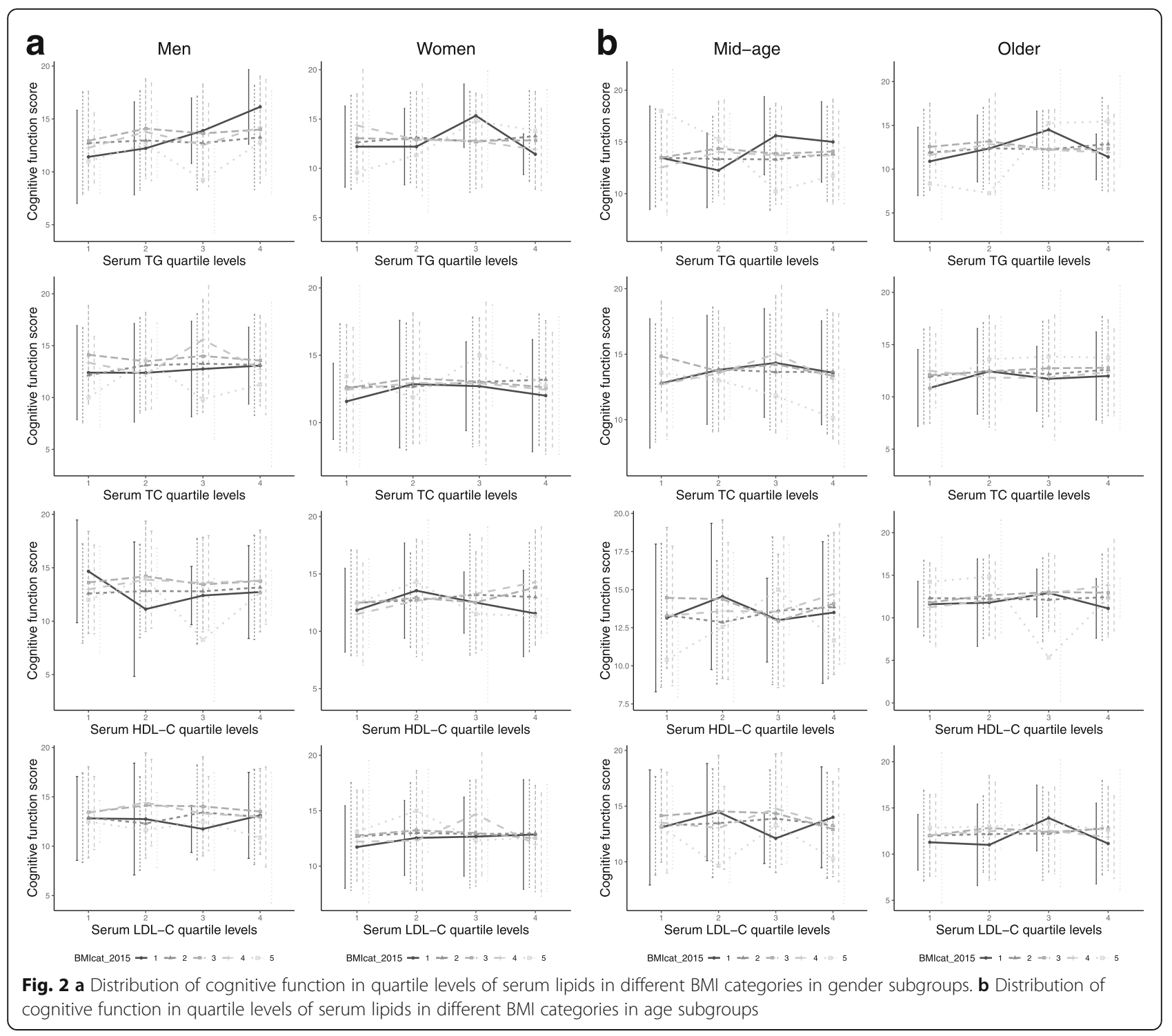

association with low TC and LDL-C levels at the same time. The possible bidirectional pathophysiological mechanisms of serum lipids with the risk of cognitive decline is that high level of cholesterol can contribute to an overproduction and accumulation of $\beta$-amyloid in the brain [7] and cholesterol is an indispensible component of neuronal and glial membranes [25]. Participants with malnutrition show alterations in the energetic profile as weight loss, reduced caloric, increased energy requirement, low lipid levels and cognitive function impairment $[8,9]$.

This study showed that gender-specific associations between serum lipids and cognitive function. Serum TG was positively associated with cognitive function score in underweight and obese male group and serum HDL-C was positively associated with cognitive function score in overweight and obese female group. Two prospective studies on metabolic syndrome have examined cognitive decline in women specifically, finding no significant association between low HDL-C or high TG and decline on global cognitive performance [26, 27]. These genderspecific inconsistent associations may be related with genetic vulnerability, serum lipid patterns, hormonal factors and the differences of cognitive function between male and female brains [24, 28, 29]. Gender-specific differences in lipid metabolism are the consequence of the action of sex chromosomes and sex-specific hormones. Women store more lipids and have higher percent bodyfat, less visceral white adipose tissue and more subcutaneous adipose tissue than men. Women have the higher rate of TG synthesis compared to men [30]. Genderspecific effects in lipid metabolism remain to be further elucidated.

Serum lipids are considered to be biomarkers of malnutrition [31] and serum TG may be a meaningful 


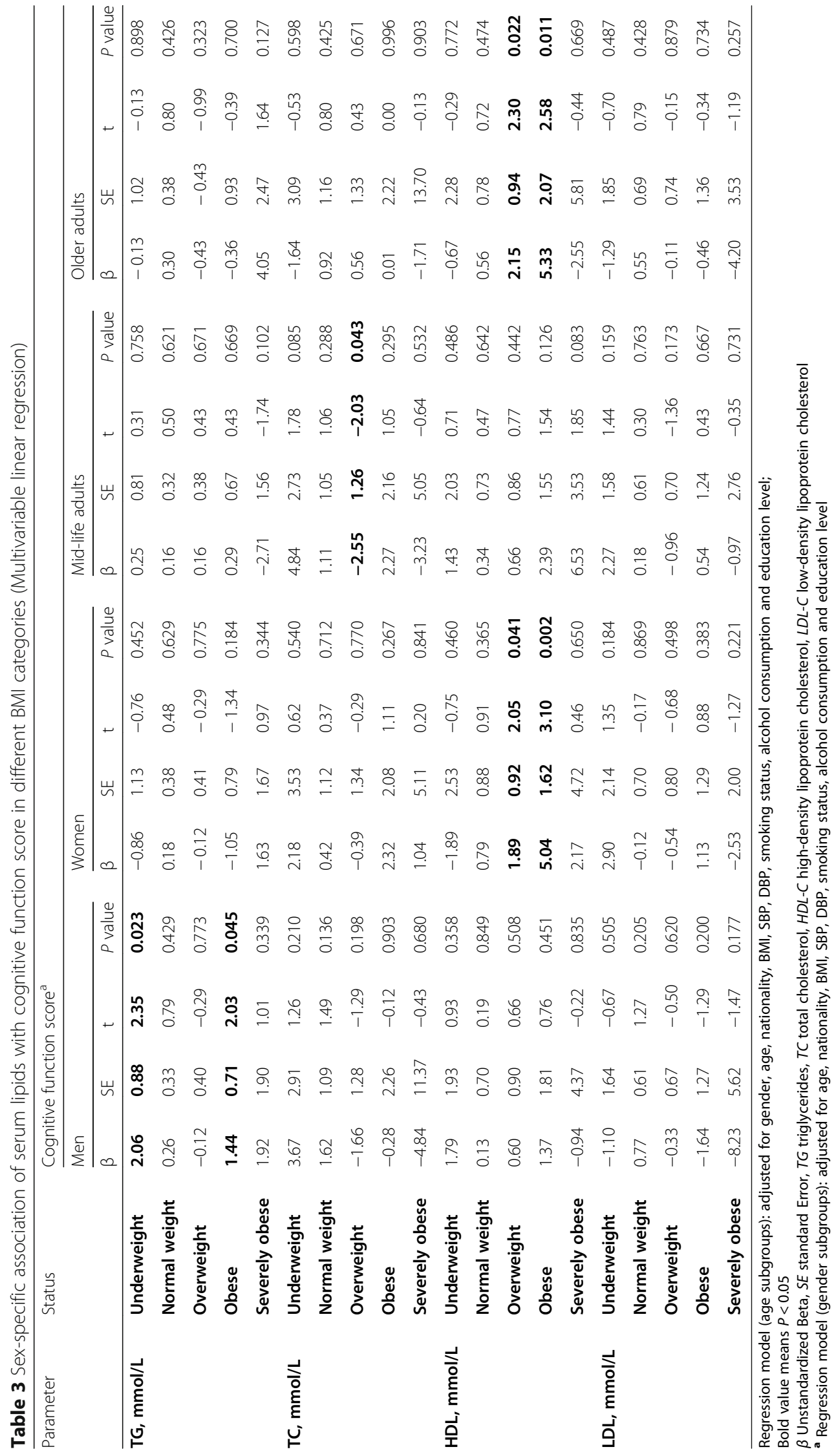


indicator of nutrition status [12, 32]. TGs can increase the blood-brain barrier transport of insulin, which can improve cognition function [33]. And higher serum TG indicates an abundance of circulating fatty acids, which can protect cognitive function and decrease the risk of dementia. This result is similar to some previous studies. Yin et al. [12] found that high normal plasma TG was associated with preservation of cognitive function in Chinese oldest-old and Ancelin et al. [24] found that TG levels were associated with a decreased risk of Alzheimer's disease in women. The reasons for these relations remain to be clarified.

Studies on the influence of body mass index on the association between serum lipids and cognitive function are limited. There is no exploring the directly relationship between serum lipids and cognitive function in different BMI levels. Lv et al. [14] found that TG was associated with MMSE score, but after adjustment for central obesity and other confounding factors, it was not associated with the risk of cognitive impairment. Of the similar studies which have examined whole samples without BMI stratification, some cross-sectional and prospective studies found inconsistent associations with serum TG (Table 1). The role of serum lipids in different BMI levels in the elderly population remains unclear. Duo to the fact that there are relatively insufficient research about the dyslipidemia and cognitive function with BMI stratification and previous findings have suggested that the impact of extremely low BMI on cognitive function is significant [34], the present study may be of special importance in filling this gap.

\section{Study strengths and limitations}

The strength of this study is related to large sample size of Chinese population to focus on the influence of BMI on the association between serum lipids and cognitive function in different sex and age subgroups.

There were several limitations of this study. First, the number and type of cognitive function tests performed at this study were limited and were not likely to provide particularly precise individual cognitive function score, such as an orientation test was not included in the analysis as it was only assessed in 2015 wave. Second, there was only 1 time point of measurement of serum lipids and assessment of cognitive function. Longitudinal analysis of the temporal relationship between serum lipids levels and cognitive function was not possible. Third, the data was adjusted by multiple confounding factors but cannot exclude the possibility of residual bias due to unmeasured confounders. Fourth, because it was an observational study, results could have been confounded by indication bias and cannot show direct causality of BMI and serum lipids with cognitive function. Last, although participants who use lipid-lowering agent were excluded, participants with hormone treatment were not excluded.

\section{Conclusions}

Results of this study showed that the relationship between serum lipids and cognitive function was related with BMI levels and differed between subgroups. Serum TG was positively associated with cognitive function score in underweight and obese male group, and serum HDL-C was positively associated with cognitive function score in overweight and obese female group and older adults. These findings suggest that the levels of blood lipids are not as low as possible. Better nutritional status may be beneficial to cognitive function. Such analytical method needs to be further replicated and it could benefit from corresponding analysis.

\section{Abbreviations}

BMI: Body mass index; CHNS: China Health and Nutrition Survey; TG: Triglyceride; TC: Total cholesterol; HDL-C: High-density lipoprotein cholesterol; LDL-C: Low-density lipoprotein cholesterol; SBP: Systolic blood pressure; DBP: Diastolic blood pressure

\section{Acknowledgements}

This research uses data from the China Health and Nutrition Survey (CHNS). We thank the National Institute for Nutrition and Health, China Center for Disease Control and Prevention, Carolina Population Center (P2C HD050924, T32 HD007168), the University of North Carolina at Chapel Hill, the NIH (R01HD30880, DK056350, R24 HD050924, and R01-HD38700) and the NIH Fogarty International Center (D43 TW009077, D43 TW007709) for financial support for the CHNS data collection and analysis files from 1989 to 2015 and future surveys, and the China-Japan Friendship Hospital, Ministry of Health for support for CHNS 2009, Chinese National Human Genome Center at Shanghai since 2009, and Beijing Municipal Center for Disease Prevention and Control since 2011. This work was supported by the National Natural Science Foundation of China (No. 81202766).

\section{Authors' contributions}

Study design: Jiang Li and Cheng Xiao. Data collection and analysis: Jiang Li and Yongtong Cao. Manuscript preparation: Jiang Li, Yongtong Cao and Cheng Xiao. The author(s) read and approved the final manuscript.

\section{Funding}

None.

\section{Availability of data and materials}

Details of the study design, sampling strategies and data are available at the World Wide Web site (https://www.cpc.unc.edu/projects/china).

\section{Ethics approval and consent to participate}

All the documentation and procedures comply with Good Clinical Practice (GCP), Human Ethics Protocol Rules and related Chinese laws. The CHNS project was approved by the office of human research ethics of the University of North Carolina at Chapel Hill and the Human \& Clinical Research Ethics Committee of China-Japan Friendship Hospital.

\section{Consent for publication}

Written informed consent for publication was obtained from all participants.

\section{Competing interests}

All authors declare that they have no conflicts of interest and are in agreement with the content of the manuscript.

\section{Author details}

${ }^{1}$ Department of Laboratory Medicine, China-Japan Friendship Hospital, Beijing 100029, China. ${ }^{2}$ Institute of Clinical Medicine, China-Japan Friendship 
Hospital, Beijing 100029, China. ${ }^{3}$ Graduate School of Peking Union Medical College, Chinese Academy of Medical Sciences/Peking Union Medical College, Beijing 100193, China.

Received: 22 December 2019 Accepted: 4 June 2020

Published online: 08 June 2020

\section{References}

1. Ma L, Zhang L, Sun F, Li Y, Tang Z. Cognitive function in Prefrail and frail community-dwelling older adults in China. BMC Geriatr. 2019;19(1):53.

2. Xue J, Li J, Liang J. The prevalence of mild cognitive impairment in China a systematic review. Aging Dis. 2018;9(4):706-15.

3. Huang CQ, Dong BR, Wu HM, Zhang YL, Wu JH, Lu ZC, et al. Association of cognitive impairment with serum lipid/lipoprotein among Chinese nonagenarians and centenarians. Dement Geriatr Cogn Disord. 2009;27(2): 111-6 Epub 2009/01/23

4. Wang X, Zhou W, Ye T, Lin X, Zhang J. Sex difference in the association of APOE4 with memory decline in mild cognitive impairment. J Alzheimer's Dis. 2019;69(4):1161-9 Epub 2019/05/28.

5. Li W, Qiu Q, Sun L, Yue L, Wang T, Li X, et al. Sex differences in obesity and cognitive function in a cognitively normal aging Chinese Han population. Neuropsychiatr Dis Treat. 2017:13:2405-10 Epub 2017/10/27.

6. Lu Y, An Y, Yu H, Che F, Zhang X, Rong H, et al. Sex-specific nonlinear associations between serum lipids and different domains of cognitive function in middle to older age individuals. Metab Brain Dis 2017;32(4): 1089-1097. Epub 2017/04/05.

7. Hughes TM, Lopez OL, Evans RW, Kamboh MI, Williamson JD, Klunk WE, et al. Markers of cholesterol transport are associated with amyloid deposition in the brain. Neurobiol Aging. 2014;35(4):802-7 Epub 2013/11/10.

8. Reitz C, Tang MX, Luchsinger J, Mayeux R. Relation of plasma lipids to Alzheimer disease and vascular dementia. Arch Neurol. 2004;61(5):705-14.

9. Oreopoulos A, Kalantar-Zadeh K, Sharma AM, Fonarow GC. The obesity paradox in the elderly: potential mechanisms and clinical implications. Clin Geriatr Med 2009;25(4):643-659, viii. Epub 2009/12/01.

10. van Vliet $P$, van de Water W, de Craen AJ, Westendorp RG. The influence of age on the association between cholesterol and cognitive function. Exp Gerontol. 2009;44(1-2):112-22 Epub 2008/06/27.

11. van Vliet P. Cholesterol and late-life cognitive decline. J Alzheimer's Dis. 2012;30(Suppl 2):S147-62 Epub 2012/01/25.

12. Yin ZX, Shi XM, Kraus VB, Fitzgerald SM, Qian HZ, Xu JW, et al. High normal plasma triglycerides are associated with preserved cognitive function in Chinese oldest-old. Age Ageing. 2012;41(5):600-6 Epub 2012/03/27

13. Corley J, Starr JM, Deary IJ. Serum cholesterol and cognitive functions: the Lothian birth cohort 1936. Int Psychogeriatr. 2015;27(3):439-53 Epub 2014/ $07 / 16$

14. Lv YB, Yin ZX, Chei CL, Brasher MS, Zhang J, Kraus VB, et al. Serum cholesterol levels within the high Normal range are associated with better cognitive performance among Chinese elderly. J Nutr Health Aging. 2016; 20(3):280-7 Epub 2016/02/20

15. Kanoski SE, Davidson TL. Western diet consumption and cognitive impairment: links to hippocampal dysfunction and obesity. Physiol Behav. 2011;103(1):59-68.

16. Parthasarathy V, Frazier D, Jastrzab L, Chao L, Chui H, Bettcher B, et al. The Effect of Triglycerides on Cognitive Function in Aging Adults: A CrossSectional Study (S58.004). 2014.

17. Popkin BM, Du S, Zhai F, et al. Cohort Profile: The China Health and Nutrition Survey--monitoring and understanding socio-economic and health change in China, 1989-2011[J]. Int J Epidemiol. 2010;39(6):1435-40.

18. Popkin B, Keyou G, Zhai F, Guo X, Ma H, Zohoori N. The nutrition transition in China: a cross-sectional analysis. Eur J Clin Nutr. 1993:47(5):333.

19. Group COW. Chinese adult overweight and obesity prevention and control guide (excerpt). Acta Nutrimenta Sinica. 2004;26(1):1-4.

20. Organization WH. Global recommendations on physical activity for health. 2010

21. Shi Z, El-Obeid T, Riley $M$, et al. High Chili Intake and Cognitive Function among 4582 Adults: An Open Cohort Study over 15 Years[J]. Nutrients. 2019;11(5):1183.

22. Plassman BL, Welsh KA, Helms M, Brandt J, Page WF, Breitner JC Intelligence and education as predictors of cognitive state in late life: a 50 year follow-up. Neurology. 1995;45(8):1446-50 Epub 1995/08/01.
23. Solomon A, Kåreholt I, Ngandu T, Wolozin B, Macdonald SWS, Winblad B, et al. Serum total cholesterol, statins and cognition in non-demented elderly. Neurobiol Aging. 2009;30(6):1006-9.

24. Ancelin ML, Ripoche E, Dupuy AM, Samieri C, Rouaud O, Berr C, et al. Gender-specific associations between lipids and cognitive decline in the elderly. Eur Neuropsychopharmacol. 2014;24(7):1056-66.

25. Pfrieger FW, Ungerer N. Cholesterol metabolism in neurons and astrocytes. Prog Lipid Res. 2011;50(4):357-71 Epub 2011/07/12.

26. Pirjo K, Lakka TA, Miia K, Maija H, Eeva-Liisa H, Irja H, et al. Metabolic syndrome and cognitive function: a population-based follow-up study in elderly women. Dement Geriatr Cogn Disord. 2007:23(1):29-34.

27. Yaffe K, Weston A. T, Krueger K. the metabolic syndrome and development of cognitive impairment among older women. Arch Neurol. 2009;66(3):324-8.

28. Casiglia E, Schiavon L, Tikhonoff V, Bascelli A, Martini B, Mazza A, et al. Electrocardiographic criteria of left ventricular hypertrophy in general population. Eur J Epidemiol. 2008;23(4):261-71 Epub 2008/03/07.

29. Neufang S, Specht K, Hausmann M, Gunturkun O, Herpertz-Dahlmann B, Fink $G R$, et al. Sex differences and the impact of steroid hormones on the developing human brain. Cereb Cortex. 2009;19(2):464-73 Epub 2008/06/14.

30. Varlamov $\mathrm{O}$, Bethea $\mathrm{CL}$, Roberts $C T$ Jr. Sex-specific differences in lipid and glucose metabolism. Front Endocrinol. 2014;5:241 Epub 2015/02/04.

31. Dana H, Radomir H, Pavel V, Petr K, Miloslav H, Zdenek Z. Serum lipids and neopterin in urine as new biomarkers of malnutrition and inflammation in the elderly. Nutrition. 2009:25(3):303-8.

32. Weir CJ, Sattar N, Walters MR, Lees KR. Low triglyceride, not low cholesterol concentration, independently predicts poor outcome following acute stroke. Cerebrovasc Dis. 2003;16(1):76-82 Epub 2003/05/27.

33. Urayama A, Banks WA. Starvation and triglycerides reverse the obesityinduced impairment of insulin transport at the blood-brain barrier. Endocrinology. 2008;149(7):3592-7 Epub 2008/04/12.

34. Suemoto CK, Gilsanz P, Mayeda ER, Glymour MM. Body mass index and cognitive function: the potential for reverse causation. Int J Obes. 2015; 39(9):1383-9 Epub 2015/05/09

\section{Publisher's Note}

Springer Nature remains neutral with regard to jurisdictional claims in published maps and institutional affiliations.
Ready to submit your research? Choose BMC and benefit from:

- fast, convenient online submission

- thorough peer review by experienced researchers in your field

- rapid publication on acceptance

- support for research data, including large and complex data types

- gold Open Access which fosters wider collaboration and increased citations

- maximum visibility for your research: over $100 \mathrm{M}$ website views per year

At BMC, research is always in progress.

Learn more biomedcentral.com/submissions 